\title{
ANALYSIS OF PREVALENCE OF SPONTANEOUS BACTERIAL PERITONITIS IN CIRRHOTIC ASCITES IN A TERTIARY CARE CENTRE IN NORTHERN TAMILNADU
}

\author{
Rajendran Thilakavathi', Parthasarathy Prathiba², Pillanallur Rajendran Saiprashanth³, Venkatachalam Vivek
}

${ }_{1}^{1}$ Associate Professor, Department of General Medicine, Government Vellore Medical College and Hospital. ${ }^{2}$ Assistant Professor, Department of General Medicine, Government Vellore Medical College and Hospital. 3 Postgraduate Student, Department of General Medicine, Government Vellore Medical College and Hospital. ${ }^{4}$ Postgraduate Student, Department of General Medicine, Government Vellore Medical College and Hospital. \begin{abstract}
BACKGROUND

Spontaneous bacterial peritonitis is defined as infected ascitic fluid in the absence of apparent intra-abdominal source of infection. Infections with more than one organism is likely to be associated with abdominal paracentesis, colonic perforation or intraabdominal source of infection. Infections among cirrhotic patients is often overlooked when compared to the attention given to its other complications.

The objective of this study is to study the prevalence of spontaneous bacterial peritonitis in patients with Alcoholic liver cirrhosis within a tertiary care centre in Northern Tamilnadu.
\end{abstract}

\section{MATERIALS AND METHODS}

This was a cross-sectional study conducted in the Department of General Medicine in Govt. Vellore Medical College for a period of 6 months, which included 102 patients with cirrhosis of liver with ascites. Patients were diagnosed as a case of cirrhosis of liver with ascites on basis of clinical evaluation, biochemical investigations, ultrasonography and UGI scopy. All the patients were chronic alcoholics and were not on any antibiotics. All patients with ascites due to other causes viz. renal, tuberculosis, malignant pathology, cholelithiasis, collagen vascular diseases etc. were excluded. Patients who were on antibiotics prior to or on admission were excluded. Patients with obvious causes of intra-abdominal infection were excluded from the study.

\section{RESULTS}

21 out of 102 patients, i.e. 20.59\% had spontaneous bacterial peritonitis. Men (80.95\%) more commonly presented with cirrhotic ascites when compared to women (19.05\%) in our study. Ascitic fluid culture from 9 patients yielded positive results by bedside blood culture bottle inoculation. 12 patients (57.14\%) were labelled as neutrocytic bacterascites. The most common organism cultured was E. coli (66.67\%).

\section{CONCLUSION}

SBP is the common overlooked complication of ascites with prevalence common among male alcoholics in age group between 30 50 years with abdominal pain, the most common precursor symptom of SBP.

\section{KEYWORDS}

Spontaneous Bacterial Peritonitis, Cirrhosis, Ascites, Chronic Alcoholism, Serum Albumin.

HOW TO CITE THIS ARTICLE: Thilakavathi R, Prathiba P, Saiprashanth PR, et al. Analysis of prevalence of spontaneous bacterial peritonitis in cirrhotic ascites in a tertiary care centre in Northern Tamilnadu. J. Evolution Med. Dent. Sci. 2018;7(04):487-491, DOI: $10.14260 /$ jemds/2018/108

\section{BACKGROUND}

Infections among cirrhotic patients is often overlooked when compared to the attention given to its other complications. Studies have shown that $30 \%-50 \%$ of cirrhotics presented with bacterial infection on admission or has developed it during the course of hospitalisation. Spontaneous bacterial peritonitis is defined as infected ascitic fluid in the absence of apparent intra-abdominal source of infection. The likely pathogenesis of SBP is that the bacteria from gut gains access to ascites via systemic circulation due to an impaired Kupffer cell function or directly from lymphatics in gut

'Financial or Other Competing Interest': None.

Submission 15-12-2017, Peer Review 10-01-2018,

Acceptance 15-01-2018, Published 22-01-2018.

Corresponding Author:

Dr. Parthasarathy Prathiba,

\#19/24, Ramanathan Street,

T. Nagar,

Chennai-600017.

E-mail: prathusarathy@gmail.com

DOI: $10.14260 /$ jemds $/ 2018 / 108$ mucosa. The infection is monobacterial in $90 \%$ cases and in $60 \%-80 \%$ cases it is due to aerobic Gram-negative bacteria. Deficiency of opsonins in ascitic fluid may lead to defective coating of bacteria, which may be indigestible by polymorphs. The deficient opsonic activity is more likely, if ascitic fluid protein is less than $1 \mathrm{mg} / \mathrm{dL}$. Infections with more than one organism is likely to be associated with abdominal paracentesis, colonic perforation or intra-abdominal source of infection. The prevalence of SBP varies from $10 \%$ to $27 \%$ among hospitalised patients with ascites and carries a $48 \%$ to $57 \%$ mortality. It is therefore essential that infection of the ascitic fluid be diagnosed early and appropriate therapy initiated. Many patients with SBP lack traditional signs and symptoms of infection such as fever, leucocytosis or abdominal pain and diagnosis is usually made based on ascitic fluid analysis. The diagnosis of SBP is made when there is a positive ascitic fluid culture and there is an elevated ascitic fluid polymorphonuclear cell count. The recurrence of SBP occurs in $70 \%$ with one year after recovery from first episode. Early treatment before shock or renal failure development reduced infection related mortality. 


\section{Aim/ Primary Objective}

To estimate the prevalence of spontaneous bacterial peritonitis in ascites of cirrhotic patients.

\section{Secondary Objectives}

1. To evaluate the clinical profile of spontaneous bacterial peritonitis.

2. To establish a correlation of ascitic fluid cell count, especially polymorphonuclear leucocyte count with the onset of spontaneous bacterial peritonitis.

3. To determine the superiority of ascitic fluid culture using blood culture media over the conventional culture methods of ascitic fluid.

4. To study the morphological profile of spontaneous bacterial peritonitis in ascites of cirrhotics.

\section{MATERIALS AND METHODS}

This was a cross-sectional study conducted in the Department of General Medicine in Govt. Vellore Medical College for a period of 6 months, which included 102 patients with cirrhosis of liver with ascites.

\section{Sample Size}

102 , estimated by convenient sampling method.

\section{Inclusion Criteria}

1. Chronic alcoholics.

2. Clinical features suggestive of cirrhosis of liver with ascites.

3. Ultrasonographic evidence of cirrhosis of liver.

\section{Exclusion Criteria}

1. All patients with ascites due to other known causes, viz. renal, tuberculosis, malignant pathology, cholelithiasis, collagen vascular diseases, etc.

2. Patients with exposure to antibiotics prior to or on admission.

3. Patients with obvious causes of intra-abdominal infection.

\section{Diagnosis of Cirrhosis of Liver}

1. Clinical features.

2. USG showing shrunken or nodular surface, increased echo texture, portal vein dilatation, > $14 \mathrm{~mm}$, splenic enlargement, prominent splenic vascular channels.

3. Total serum protein, albumin, globulin, A and G ratio, SAAG was considered corroborative for cirrhosis.

4. Liver biopsy as a diagnostic tool was not considered due to patient's non-compliance.

5. Special attention was paid to ascitic fluid polymorphonuclear leucocyte count and ascitic fluid culture.

\section{Technique of Ascitic Fluid Tap}

Z-track technique was used for ascitic fluid collection, $15 \mathrm{~mL}$ aspirated and inoculated into blood culture bottle. The bottles were incubated for 72 hours and organisms isolated and identified. About $1 \mathrm{~mL}$ of fluid was sent for count and cell count was done immediately. $3 \mathrm{~mL}$ of fluid was sent for biochemical analysis.

\section{Statistical Analysis}

Statistical analysis was done using SPSS v 16 software.

\section{RESULTS}

Among the study population of 102 patients, the mean age was 42.3 years. All cases were above 20 years of age. Men more commonly presented with cirrhotic ascites compared to women in our study. Out of 102 patients, 79 cases were male and 23 patients were females. Among them spontaneous bacterial peritonitis was present in 17 male patients (80.95\%) and 4 female patients (19.05\%).

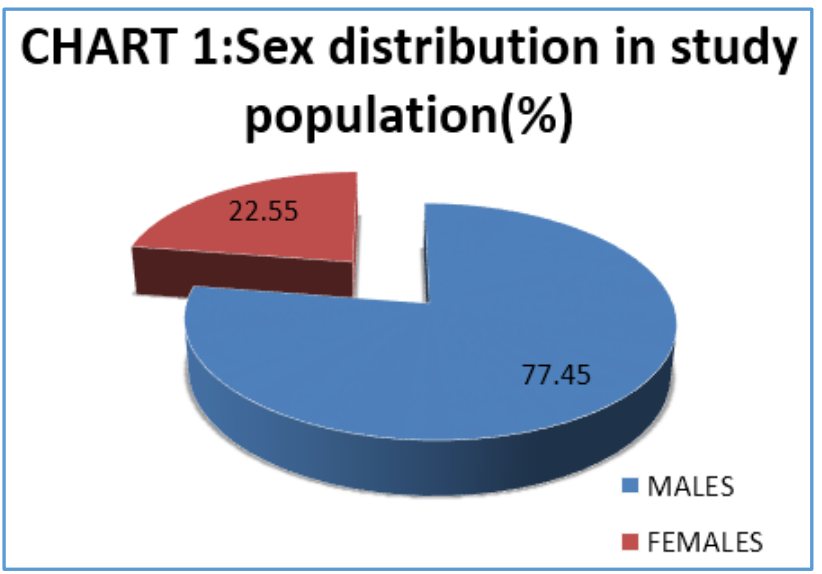

21 patients (20.59\%) out of 102 patients had spontaneous bacterial peritonitis. 7 patients out of 21 patients with SBP, i.e. $33.33 \%$ were in the age group of $31-40$ years. 6 out of 21 patients with SBP, i.e. 28.57\% were from 41-50 years of age. 3 patients (14.29\%) belonged to the age group of 21-30 years. 3 patients (14.29\%) were from 51-60 years of age and 2 patients $(9.52 \%)$ were from $61-70$ age group. In the study population the most common symptom was abdominal pain with 36 patients reporting it, out of which 17 patients (80.95\%) had evidence of SBP (Table 1).

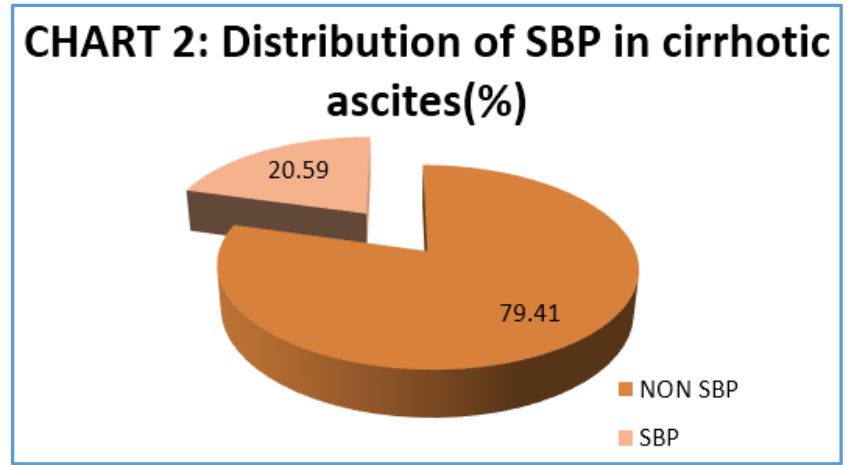

Serum albumin was reduced in all 21 patients with SBP with a mean of $2.08 \mathrm{gm} / \mathrm{dL}$ (Table 2). Serum bilirubin was elevated in 10 patients $(47.61 \%)$ with a mean level of 3.29 $\mathrm{mg} / \mathrm{dL}$. Prothrombin levels were prolonged by at least 2 times than that of control in 12 patients (57.14\%) with SBP. AST was elevated in $61.90 \%$ and ALT was elevated in $42.86 \%$ of patients. HBsAg was positive for 4 cases (19.05\%) of SBP patients. 


\begin{tabular}{|c|c|c|}
\hline $\begin{array}{l}\text { Symptoms and } \\
\text { Signs }\end{array}$ & $\begin{array}{l}\text { No. of Patients } \\
\quad(\mathrm{N}=102)\end{array}$ & $\begin{array}{l}\text { No. of Patients } \\
\text { with } S B P(N=21)\end{array}$ \\
\hline Abdominal pain & 36 & $17(80.95 \%)$ \\
\hline Fever & 24 & $15(71.43 \%)$ \\
\hline $\begin{array}{l}\text { Abdominal } \\
\text { tenderness }\end{array}$ & 33 & $14(66.67 \%)$ \\
\hline $\begin{array}{c}\text { Hepatic } \\
\text { encephalopathy }\end{array}$ & 15 & $4(19.04 \%)$ \\
\hline GI bleed & 42 & $12(57.14 \%)$ \\
\hline H/O Alcohol intake & 68 & 16 \\
\hline \multicolumn{3}{|c|}{$\begin{array}{c}\text { Table 1. Distribution of Symptoms and Signs in Cirrhotic } \\
\text { Patients with SBP }\end{array}$} \\
\hline
\end{tabular}

\begin{tabular}{|c|c|c|}
\hline Biochemical Profile & $\begin{array}{c}\text { No. of } \\
\text { Patients } \\
(\mathbf{N = 1 0 2})\end{array}$ & $\begin{array}{c}\text { No. of Patients } \\
\text { with SBP } \\
\text { (N= 21) }\end{array}$ \\
\hline Sr. Bilirubin $(\mu=3.29 \mathrm{mg} / \mathrm{dL}) \uparrow$ & 42 & 10 \\
\hline Sr. Albumin $(\mu=2.08 \mathrm{gm} / \mathrm{dL}) \downarrow$ & 58 & 21 \\
\hline AST $\uparrow$ & 55 & 13 \\
\hline ALT $\uparrow$ & 34 & 9 \\
\hline PT $\uparrow$ & 37 & 12 \\
\hline HBsAg positive & 10 & $4(19.05 \%)$ \\
\hline \multicolumn{2}{|c|}{ Table 2. Analysis of Biochemical Profile } \\
\hline
\end{tabular}

Ascitic fluid protein was reduced in all patients of SBP. The range was 0.8 to 1.2 gms $\%$ with a mean level of 0.88 g/dL. Polymorphonuclear leukocyte count was raised more than 250 cells $/ \mathrm{mm}^{3}$ in all 21 patients of SBP out of the 102 patients. Three cases of SBP showed positive smears on grams stain. Ascitic fluid culture yielded positive results in 9 patients (42.86\%) by bedside blood culture bottle inoculation method (Table 3 ), of which 3 were positive by conventional method. In 12 patients (57.14\%) no organisms were isolated, and these were labelled as culture negative neutrocytic bacterascites. Culture of ascitic fluid showed E. coli growth in 6 patients with spontaneous bacterial peritonitis, while Klebsiella pneumoniae was isolated in 2 cases and staphylococcus was isolated in case. Urine culture was positive for 2 patients (Table 4).

\section{CHART 3:MICROBIOLOGICAL PROFILE IN PATIENTS WITH SBP}

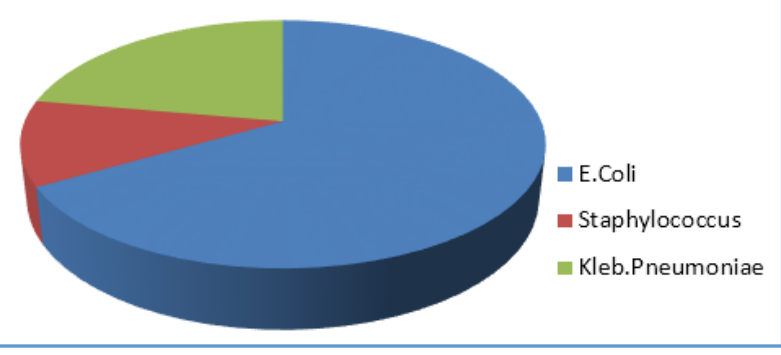

\begin{tabular}{|c|c|c|}
\hline Organism & $\begin{array}{c}\text { No. of Patients } \\
\text { with SBP (N= 21) }\end{array}$ & $\begin{array}{c}\text { \% Patients with } \\
\text { SBP }\end{array}$ \\
\hline E. coli & 6 & 66.67 \\
\hline $\begin{array}{c}\text { Klebsiella } \\
\text { pneumoniae }\end{array}$ & 2 & 22.22 \\
\hline Staphylococcus & 1 & 11.11 \\
\hline \multicolumn{2}{|c|}{ Table 3. Organism in Culture Positive SBP Patients } \\
\hline
\end{tabular}

\begin{tabular}{|c|c|c|}
\hline Organism & $\begin{array}{c}\text { Blood Culture } \\
\text { Positive }\end{array}$ & $\begin{array}{c}\text { Urine Culture } \\
\text { Positive }\end{array}$ \\
\hline E. coli & 2 & 1 \\
\hline Klebsiella species & - & 1 \\
\hline Staphylococcus & 1 & - \\
\hline \multicolumn{2}{|c|}{ Table 4. SBP and associated Blood and Urine Culture } \\
Positivity \\
\hline
\end{tabular}

\section{DISCUSSION}

Spontaneous bacterial peritonitis is a life-threatening complication in patients with cirrhotic ascites. The mortality from SBP has been diminishing in recent years due to better recognition and treatment.

In our study the prevalence of spontaneous bacterial peritonitis in cirrhotic ascites was $20.59 \%$. This study wherein consecutive patients with cirrhosis admitted to the hospital were included which constituted $77.45 \%$ male cirrhotic, while the female cirrhotics constituted $22.54 \%$. Most of the patients with spontaneous bacterial peritonitis were males which constituted $80.95 \%$, only $19.05 \%$ of the patients were females.

SBP was most common in the age group of 30 - 50 years in the present study. Studies reported that there is a correlation of SBP with age group. ${ }^{1}$ This may be due to early access to medical care and better nutrition compared to the economic strata of a patient coming to a government hospital.

On the basis of a large proportion of cirrhotics in our region being due to chronic alcohol intake. Female alcoholics are fewer in our country, which possibly contributes to the lower incidence of SBP. Although, typically both sexes are affected equally. ${ }^{2}$

The prevalence of SBP in liver cirrhosis is estimated to be $7 \%-30 \% .^{3-7}$ The numbers have not increased over the past 20 to 30 years even with factors like increased awareness of the condition and also lower threshold for doing diagnostic paracentesis. A study done by Runyon BA et al in 1986 reported the prevalence of spontaneous bacterial peritonitis was $10 \%$ to $27 \%$ of cirrhotic patients. Puri AS et al from North India in 1996 reported that the prevalence was 30\%. In our study the prevalence was $20.59 \%$, which reiterate the facts that hitherto nothing much has changed. Exceptions are far and few with studies done in Africa and Pakistan showing prevalence rate more than $50 \% .{ }^{8}$

Mortality rates have drastically come down to nearly $20 \%-30 \%$ from an earlier high of $80 \%-90 \%{ }^{9,10}$ with early diagnosis and treatment. In studies conducted in various parts of globe, very large differences in mortality were reported. Hoefs JC et al reported a mortality of $48.95 \%$. Puri AJ et al report of in-hospital mortality in SBP was of $28.6 \%$. A large percentage of patients had abdominal pain $(80.95 \%)$. Hence abdominal pain in a cirrhotic ascites carries a high index of suspicion of SBP, which warrants further relevant investigation. Similarly, a strong positive correlation of SBP occurs in cirrhotics presenting with fever (71.43\%) and abdominal tenderness (66.67\%). Runyon BA et al reported $87 \%$ of SBP patients were symptomatic at the time of diagnosis of infection. The symptoms and signs of infection were often subtle, such as slight changes in mental status. UGI bleed associated with SBP was noted in $57.14 \%$. GI bleeding has been shown to be associated with an increase in the bacterial translocation from the intestinal lumen and an impairment in the reticuloendothelial function. An association between the development of SBP and GI bleeding 
was reported by Carey et al. Several studies reported that the serum albumin was depressed in all the patients with cirrhotic ascites with SBP.11,12 The serum albumin was reduced in all 21 patients with SBP in our study.

The protein concentration of cirrhotic ascites, essentially and entirely determined by serum protein concentration and portal pressure. The low serum albumin level reflects advanced liver disease, which is associated with impaired reticuloendothelial function. Studies have reported that patients who have $(>2.5 \mathrm{mg} / \mathrm{dL})$ high bilirubin/ elevated enzyme level with low ascitic protein concentration are more prone to develop SBP. ${ }^{2,13}$ In our study, the serum bilirubin was elevated in $47.61 \%$ of patients with SBP. Aspartate aminotransferase and alanine aminotransferase levels were elevated in $61.90 \%$ and $42.86 \%$ respectively. Of the 2, aspartate aminotransferase had a more positive correlation. Prothrombin time was prolonged in $57.14 \%$, probably due to hypercoagulable state secondary to liver disease. Coagulation factor deficiencies/ hypofibrinogenaemia may be responsible for the hypocoagulability. Patients with protein level of ascitic fluid less than $1 \mathrm{gm} / \mathrm{dL}$ developed SBP ten times more often than patients with initial ascitic fluid protein more than 1 $\mathrm{gm} / \mathrm{dL} \cdot{ }^{14}$ In our study ascitic fluid protein was low in patients with SBP compared to that of non-SBP group, the mean level was $0.88 \mathrm{gm} / \mathrm{dL}$

SBP is uncommon in patients with ascites of neoplastic origin, who present with very high ascitic fluid protein concentration. The ascitic fluid protein concentration is remarkably low in cirrhotic patients admitted to hospital with ascites with SBP than in those admitted only for ascites. The total protein concentration correlated closely with the ascitic fluid concentration of protein with antibacterial activity. These proteins like fibronectin and complement components along with ascitic fluid opsonic activity have provided a rational basis for positive correlation. Albilos A et al reported SBP was diagnosed early and best by the increased polymorphonuclear leukocyte count. The ascitic fluid PMN cell count was higher than $250 / \mathrm{mm}^{3}$. The short survival of PMN cells results in relative stability in the absolute PMN count during diuresis. Therefore, the $250 / \mathrm{mm}^{3}$ cut-off remains reliable even at the end of diuresis. $33.33 \%$ of SBP were culture positive, gram staining revealed organism. Gram staining of ascitic fluid is most helpful in the diagnosis of free perforation of the gut into ascites rather than in primary spontaneous peritonitis. Ascitic fluid culture were done by a conventional method using agar plates and bedside inoculation using blood culture bottle.

Culture was in $42.86 \%$ positive by bedside inoculation method and $14.29 \%$ were positive by conventional culture method. 14-15 This supports Runyon BA et al's results, which demonstrated superior sensitivity by using blood culture bottles for culture of ascitic fluid compared with conventional techniques. E. coli was the most common organism isolated in $66.67 \%$. Klebsiella pneumonia was isolated in $22.22 \%$ and Staphylococcus in $11.11 \%$ of patients. In this study, culture negative neutrocytic bacterascites were $57.14 \%$. Monobacterial bacterascites was noted in $42.86 \%$. Llovet JM et al demonstrated $30-40 \%$ of patients had culture negative SBP. 16

The patients included in the study denied any prior antibiotic use. It is also possible that the load of bacteria in most of those patients was low for a viable culture. This could explain the relatively higher proportion of CNNA variant of SBP among patients. As enteric organisms from the gut translocate to cause SBP, E. coli is the commonest. Our study revealed an incidence of $66.67 \%$ of E. coli infection in SBP. Similar findings were seen in other studies as well.1,2,17 Blood culture was positive in 3 patients of SBP and 2 patients had associated infection in urine by the same organism. Most important determining factor for the development of SBP may be a source of infection with the potential for bacteraemia. The already weakened reticuloendothelial system would allow even a transient bacteraemia to persist long enough to seed the ascitic fluid, a fluid that is low in complement and opsonic activity. The alternative hypothesis for the association between urinary tract infection and SBP is that bacteria first gain access to the peritoneal fluid and cause the infection and disseminate resulting in bacteraemia and bacteriuria. In this study, some related findings are seen. Bacteraemia rarely occurs in SBP of cirrhotic ascites.

\section{CONCLUSION}

Spontaneous bacterial peritonitis is a common, but usually overlooked complication of cirrhosis with ascites. SBP occurs in approximately $20.59 \%$ of cirrhotic patients with ascites. More than $50 \%$ of patients were in the age group of $30-50$ years. Males were more affected than females, possibly due to associated alcoholism. Abdominal pain in cirrhosis seem to be a significant predictor for development of SBP. Fever, abdominal tenderness were common in SBP with cirrhotic ascites. GI bleed commonly precedes the occurrence of SBP. Hepatic encephalopathy correlated poorly with the incidence of SBP.

\section{REFERENCES}

[1] Ho H, Zuckerman MJ, Ho TK, et al. Prevalence of associated infections in community-acquired spontaneous bacterial peritonitis. American Journal of Gastroenterology 1996;91(4):735-42.

[2] Oladimeji AA, Temi AP, Adekunle AE, et al. Prevalence of spontaneous bacterial peritonitis in liver cirrhosis with ascites. The Pan African Medical Journal 2013;15:128.

[3] Wiest R, Krag A, Gerbes A. Spontaneous bacterial peritonitis: recent guidelines and beyond. Gut 2012;61(2):297-310.

[4] Evans LT, Kim WR, Poterucha JJ, et al. Spontaneous bacterial peritonitis in asymptomatic outpatients with cirrhotic ascites. Hepatology 2003;37(4):897-901.

[5] Mohan P, Venkataraman J. Prevalence and risk factors for unsuspected spontaneous ascitic fluid infection in cirrhotics undergoing therapeutic paracentesis in an outpatient clinic. Indian Journal of Gastroenterology 2011;30(5):221-4.

[6] Kamani L, Mumtaz K, Ahmed US, et al. Outcomes in culture positive and culture negative ascitic fluid infection in patients with viral cirrhosis: cohort study. BMC Gastroenterol 2008;8:59.

[7] Salerno F, Cazzaniga M. Therapeutic strategies and emergence of multiresistant bacterial strains. Intern Emerg Med 2010;(5 Suppl 1):S45-S51. 
[8] Memon AQ, Memon G, Khaskheli A. Spontaneous bacterial peritonitis in cirrhosis with ascites- an experience at $\mathrm{PMCH}$ Nawabshah. Med Channel 1999;5:31-4.21.

[9] Garcia-Tsao G. Current management of the complications of cirrhosis and portal hypertension: variceal hemorrhage, ascites and spontaneous bacterial peritonitis. Gastroenterology 2001;120(3):726-48.

[10] Tandon P, Garcia-Tsao G. Bacterial infections, sepsis and multiorgan failure in cirrhosis. Semin Liver Dis 2008;28(1):26-42.

[11] Kasztelan-Szczerbinska B, Słomka M, Celinski K, et al. Prevalence of spontaneous bacterial peritonitis in asymptomatic inpatients with decompensated liver cirrhosis - a pilot study. Advances in Medical Sciences 2011;56(1):13-7.

[12] Albillos A, Cuervas-Mons V, Millan I, et al. Ascitic fluid polymorphonuclear cell count and serum to ascites albumin gradient in the diagnosis of bacterial peritonitis. Gastroenterology 1990;98(1):134-40.
[13] Andreu M, Sola R, Sitges-Serra A, et al. Risk factors for spontaneous bacterial peritonitis in cirrhotic patients with ascites. Gastroenterology 1993;104(4):1133-8.

[14] Runyon BA, Antillon MR, Akriviadis EA, et al. Bedside inoculation of blood culture bottles with ascitic fluid is superior to delayed inoculation in the detection of spontaneous bacterial peritonitis. Journal of Clinical Microbiology 1990;28(12):2811-12.

[15] Parsi MA, Atreja A, Zein NN. Spontaneous bacterial peritonitis: recent data on incidence and treatment. Cleveland Clinic Journal of Medicine 2004;71(7):56976.

[16] Llovet JM, Planas R, Morillas R, et al. Short-term prognosis of cirrhotics with spontaneous bacterial peritonitis: multivariate study. American Journal of Gastroenterology 1993;88(3):388-92.

[17] Gill AS, Singh A, Matreja PS, et al. Spontaneous bacterial peritonitis in alcoholic cirrhosis: an indian perspective. Euroasian Journal of HepatoGastroenterology 2012;2(1):14-19. 